\title{
Metallurgical and Electrochemical characterization of a Supermartensitic Steel
}

\author{
Renata Braga Soares ${ }^{a, *} \mathbb{D}$, Luís Frederico Pinheiro Dick ${ }^{b}$, Sara Matte Manhabosco ${ }^{b,}$ Alvaro Pritzel dos \\ Santos $^{b}$, Wagner Reis da Costa Campos ${ }^{\circledR}$, José Domingos Ardisson ${ }^{c}$, Vanessa de Freitas Cunha Lins ${ }^{a} \mathbb{D}$ \\ ${ }^{a}$ Laboratório de Corrosão e Engenharia de Superfície, Universidade Federal de Minas Gerais, Belo \\ Horizonte, MG, Brasil. \\ ${ }^{b}$ Laboratório de Processos Eletroquímicos e Corrosão, Universidade Federal do Rio Grande do Sul, Porto \\ Alegre, RS, Brasil. \\ ${ }^{c}$ CDTN-Nuclear Energy Research Center, Belo Horizonte, MG, Brasil.
}

Received: April 04, 2019; Revised: August 25, 2019; Accepted: April 14, 2020.

\begin{abstract}
The pitting corrosion of supermartensitic stainless steel (SMSS) was studied in an aqueous solution of $0.1 \mathrm{~mol} / \mathrm{L} \mathrm{NaCl}$ using the scanning vibrating electrode technique (SVET) and cyclic voltammetry. The SMSS showed $0.9 \%$ of retained austenite, as verified by Mössbauer spectroscopy. Cuboidal TiN particles were identified on the steel surfaces, by using optical, scanning electron, and transmission microscopy, associated to $\mathrm{Mg}-\mathrm{Ca}-\mathrm{Al}$ rich precipitates. Pit nucleation was slow and only verified after $24 \mathrm{~h}$, associated to $\mathrm{TiN} / \mathrm{CaO} \cdot \mathrm{MgO} \cdot \mathrm{Al}_{2} \mathrm{O}_{3}$ complex inclusions, thus on original interdendritic spaces, where lower $\mathrm{Cr}$ content and the presence of inclusions are expected.
\end{abstract}

Keywords: Supermartensitic stainless steels, Pitting corrosion, Titanium nitride, Microstructural characterisation.

\section{Introduction}

Supermartensitic stainless steels (SMSS) are being increasingly used in the oil and gas industry due to their mechanical and chemical properties adequate to the service in environments containing chlorides, $\mathrm{CO}_{2}$ and $\mathrm{H}_{2} \mathrm{~S}$. Thus, SMSS have increasingly replaced the more expensive duplex stainless steels in many onshore and offshore applications as a constituent of seamless steel pipes for use in drilling oil and $\operatorname{gas}^{1-6}$. As an improvement to conventional martensitic stainless steels, SMSS contains up to $3 \mathrm{wt} . \%$ molybdenum, conferring a higher corrosion resistance to localized corrosion. Ilevbare and Bernstein ${ }^{7}$ reported insoluble molybdates are formed with the metal cations in the pits of steels containing molybdenum, and that molybdates were found to inhibit pitting corrosion especially in the metastable pitting stage. Bastidas et al. ${ }^{8}$ reported that in the presence of Mo, less chlorine is introduced into the passive film of AISI 316L SS during its formation and growth in relation to the AISI 304L. The SMSS also contains up to $6 \mathrm{wt}$ \% more nickel to allow the formation of austenite $(\gamma-\mathrm{Fe})$ at elevated temperatures and thus of martensite during cooling. On the other hand, the carbon content reduced down to $0.01 \mathrm{wt} . \%$ to improve the weldability ${ }^{9,10}$ avoids the precipitation of $\mathrm{Cr}$ carbides and sensitization.

According Pereda et al. ${ }^{11}$, corrosion behavior of SMSS depends on the present metallurgical phases such as retained austenite and delta ferrite, being demonstrated that the breakdown potential increases with the increase of retained austenite content. The tempered microstructure of SMSS is

*e-mail: renatabragasoares@yahoo.com.br characterized by the presence of lath martensite and that of reverse austenite finely dispersed between martensite laths promoting a high strength, toughness ${ }^{12}$. On the other hand, it has been reported that the precipitation of chromium nitrides or carbides promoted by the presence of delta ferrite is deleterious to the corrosion resistance of the alloy ${ }^{11}$.

The scanning vibrating electrode technique (SVET) under simultaneous polarization have been used to study the localized corrosion of alloys that resist pitting corrosion under open circuit potential (OCP) conditions ${ }^{13-18}$. Aiming to identify possible nucleation sites of pitting on SMSS surfaces and to elucidate the corrosion mechanisms, SVET and cyclic voltammetry were used in this work in association to different characterization techniques, as scanning electron microscopy (SEM), optical microscopy (OM), X-ray diffraction (XRD), Mössbauer spectroscopy (MS) and electron backscattering diffraction (EBSD).

\section{Experimental}

SMSS samples were cut from the transversal cross section of a seamless stainless steel tube. The chemical composition determined by the manufacturer with a PDA-7000 Shimadzu inductively coupled plasma optical emission spectroscope (ICP-OES) is listed in Table 1.

After austenitizing at $1000^{\circ} \mathrm{C}$, the samples were waterquenched and then tempered for $30 \mathrm{~min}$ within a temperature range of $600-640{ }^{\circ} \mathrm{C}$ to a final Vickers hardness (300 gf) of $261 \pm 9 \mathrm{HV}$. The samples were sanded with $\mathrm{SiC}$ paper with decreasing gran sizes and then polished with a 0.25 
Table 1. Chemical analysis of the supermartensitic stainless steel.

\begin{tabular}{lccccccccccc}
\hline Element & $\mathbf{C}$ & $\mathbf{C r}$ & $\mathbf{N i}$ & $\mathbf{M o}$ & $\mathbf{S i}$ & $\mathbf{M n}$ & $\mathbf{P}$ & $\mathbf{S}$ & $\mathbf{N}$ & $\mathbf{A l}$ & $\mathbf{T i}$ \\
\hline wt. $\%$ & $<0.01$ & 12.2 & 5.63 & 1.86 & 0.21 & 0.52 & 0.023 & 0.004 & 0.026 & 0.015 & 0.17 \\
\hline
\end{tabular}

$\mu \mathrm{m}$ diamond particles suspension. Samples were etched in Villella's reagent $(1 \mathrm{~g}$ picric acid $+4 \mathrm{~mL} \mathrm{HCl}+96 \mathrm{~mL}$ ethanol) for $15 \mathrm{~s}$.

A Tecnai G2-20 - SuperTwin FEI - 200kV transmission electron microscope (TEM) was used to analyze the precipitates. The steel microstructure was characterized using different techniques: optical microscopy (OM, Olympus) with image analysis, scanning electron microscopy with energy dispersive X-ray spectrometry (SEM-EDS, Quanta FEG 3D FEI-BrukerXFlash 4.0), X-Ray diffraction (XRD, steps of $0.05^{\circ} / 3 \mathrm{~s}$, Shimadzu). EDS coupled with SEM is able to semi-quantitatively identify the chemical composition of precipitates. X-ray diffraction identified phases such as martensite and retained austenite in SMSS. But the amount of retained austenite was too low for a quantitative determination of its the volume fraction by the Rietveld method.

Conversion electron Mössbauer spectroscopy (CEMS) was used to quantify martensite and retained austenite phases. These analyses were performed with a constant acceleration in the CEMS setup mode, using a $\sim 80 \mathrm{mCi}^{57} \mathrm{Co}$ source in $\mathrm{Rh}$ matrix, at room temperature. The gamma ray-detector was a proportional counter with a flowing gas composed of a work mixture of $95 \% \mathrm{He}$ and $5 \% \mathrm{CH}_{4}$. The collected data were numerically fitted with the NORMOS $90^{\circledR}$ computer program ${ }^{19}$. These results were analyzed based mainly on the isomer shift $(\delta)$ values, which is a spectrometric parameter that reflects the s-electron density at the ${ }^{57} \mathrm{Fe}$ nucleus, providing clues about the: (i) oxidation state of iron composing the sample; (ii) electronegativity of the ligands and (iii) electronic configuration. These isomer shift values are relative to the natural $\mathrm{Fe}(\alpha \mathrm{Fe}){ }^{20}$ : The isomer shift is spectrometrically taken as the distance between the centroid of the spectrum for the sample and the zero velocity of the scale set from the $\alpha \mathrm{Fe}$ spectrum at the same experimental conditions; the positive velocity corresponds to the source moving toward the absorber ${ }^{21}$. The obtained 298 K-Mössbauer spectra are plotted as the relative transmission of gamma rays versus the Doppler velocity of the radioactive source.

The EBSD technique was able to evaluate the maximum grain size of the sample tempered at a temperature range of $600-640^{\circ} \mathrm{C}$. The EBSD maps of representative samples were obtained using a FEI QUANTA 650 microscope coupled with the Nordlys HKL Fast Acquisition EBSD system operated at $20 \mathrm{kV}$ and step sizes of $0.5 \mu \mathrm{m}$. Grain boundaries were determined as the boundaries with misorientation larger than $15^{\circ}$. A grain was defined as a region completely surround by the boundaries defined previously $\left(>15^{\circ}\right)^{10,22}$. The data processing was carried out using the software HKL Channel 5.

All electrochemical experiments were performed in an aqueous solution of $0.1 \mathrm{~mol} / \mathrm{L} \mathrm{NaCl}$ solution in triplicates at room temperature $\left(\approx 25^{\circ} \mathrm{C}\right)$. The open circuit potential (OCP) was followed for 3600 seconds. Cyclic voltammetry (CV) was performed by using an Autolab PGSTAT 100N potentiostat in a conventional three-electrode cell $\left(1 \mathrm{~cm}^{2}\right.$ SMSS working electrode, $\mathrm{Ag} / \mathrm{AgCl} /$ saturated $\mathrm{KCl}$ reference electrode, Pt mesh counter electrode). CVs were acquired starting at $30 \mathrm{mV}$ below OCP at scan rates of 1 and $10 \mathrm{mV} / \mathrm{s}$ in the positive direction. The scan direction was reversed when the current density achieved approximately $1 \mathrm{~mA} /$ $\mathrm{cm}^{2}$. The conventional $\mathrm{CV}$ technique is able to evaluate the passivation region, the passive current density, the breakdown and protection potentials, indicating the steel repassivation capacity.

To verify the distribution of anodic and cathodic currents on the steel surface, current density maps were acquired at OCP conditions using an Applicable Electronics SVET assembly. For this, a Pt/Ir microelectrode with a diameter of $10 \mu \mathrm{m}$ vibrated with amplitude of $10 \mu \mathrm{m}$ at a distance of 50 $\mu \mathrm{m}$ from the sample surface in a barnacle electrochemical cell with a volume of approximately $0.5 \mathrm{~mL}$ fixed on the steel surface with epoxy resin. The window exposed to the electrolyte was delimited using a $60 \mu \mathrm{m}$ scotch tape (3M) delimited with epoxy resin. The acquisition process of each i-map lasted about $15 \mathrm{~min}$.

\section{Results and Discussion}

\subsection{Material characterization}

The OM and the SEM micrographs of the tempered SMSS are shown in Figure 1a and b, respectively. The microstructure consists of lath martensite. Coarse cuboidal particles are sparsely found (Figures $1 \mathrm{~b}$ and $2 \mathrm{a}$ ), which can be identified as TiN (EDS in Figure 2b) as expected for the Ti (0.17 wt.\%) and N (0.026 wt.\%) contents of this steel (Table 1). The TiN inclusions often contain one or more nuclei with homogenous electron contrast (Figure $2 \mathrm{c}$ and $\mathrm{e}$ ) of a Al-Mg-Ca-O rich phase, as the EDS maps and line scans of Figure $2 \mathrm{~d}$ and $\mathrm{f}$ show, indicating they consist of a mixed oxide of this elements, here referred as $\mathrm{MgO} \cdot \mathrm{Al}_{2} \mathrm{O}_{3} \cdot \mathrm{CaO}$. Some TiN inclusions contained microvoids or fractures as shown in Figure 2c. TEM and EDS (Figure 3b) analysis confirmed the presence of TiN particles with hexagonal crystal habit precipitated intragranularly in the SMSS matrix, as shown in Figure 3.

TiN is one of the most insoluble nitrides in steel and TiN particles are known to precipitate in the steel melt at higher temperatures owing to the high Ti-N affinity ${ }^{23-27}$. According to Shi et al. ${ }^{28}$, alumina and magnesium aluminate inclusions can provide heterogeneous nucleation sites for 


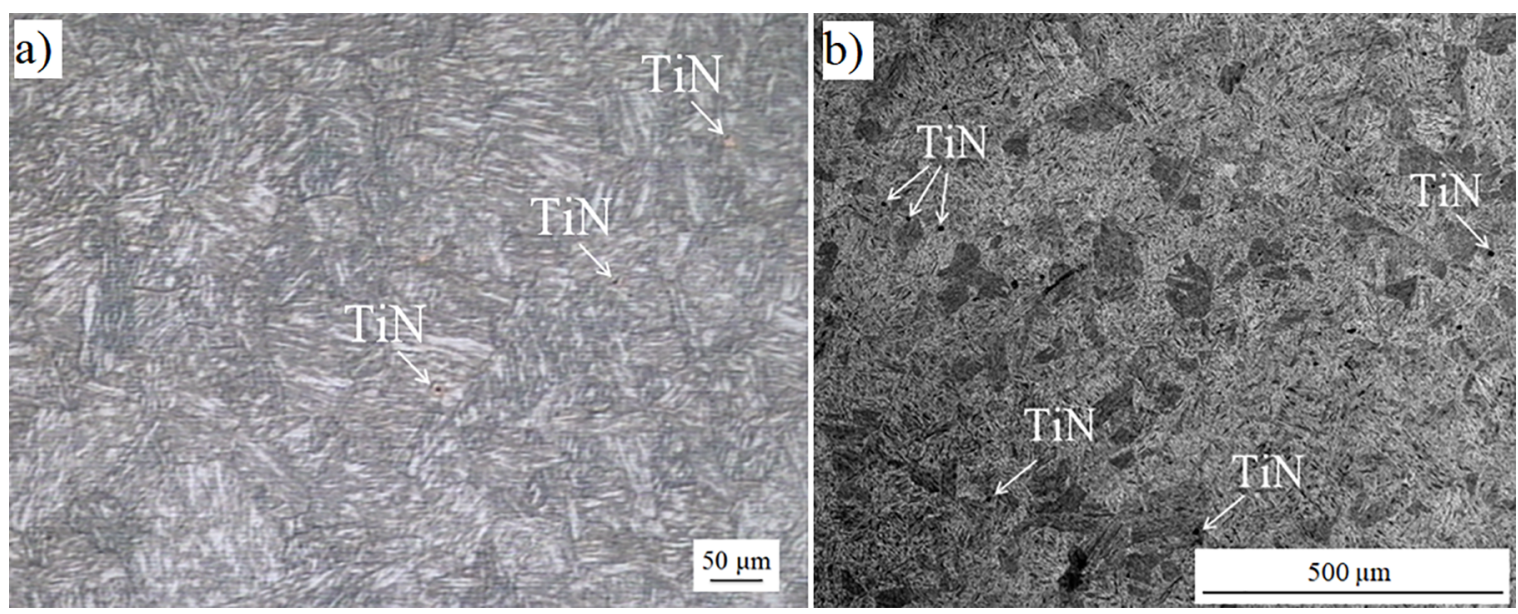

Figure 1. Microstructure of the supermartensitic steel: (a) OM and (b, c, d) SEM. TiN indicated by arrows.

primary carbides and nitrides in high-carbon steels. Meng et al. ${ }^{27}$ also observed the presence of magnesium-aluminum mixed oxide $\left(\mathrm{MgO} \cdot \mathrm{Al}_{2} \mathrm{O}_{3}\right)$ particles at the nucleus of TiN inclusions in alloy 690TT (Ni-30Cr-10Fe). During melting, particles of the refractory material containing $\mathrm{MgO}$ and $\mathrm{Al}_{2} \mathrm{O}_{3}$ are picked up and act as nucleation sites for TiN inclusions during the solidification process ${ }^{27}$. On the other hand, the verified presence of $\mathrm{Ca}$ indicates that these embedded oxide particles have a low melting point. Specifically, for Ca-modified Al-Mg oxides a melting point of $1604{ }^{\circ} \mathrm{C}$ have been cited, which is much lower than the respective values for TiN and magnesium aluminates $(\approx 2135$ $\left.{ }^{\circ} \mathrm{C}\right){ }^{29}$. However, upon solidification, the further growth of primary TiN particles has been observed due to diffusion of Ti and $\mathrm{N}$ during cooling ${ }^{23}$. Yang et al. ${ }^{23}$ reported that upon precipitation, an obvious growth of titanium nitride on a primary inclusion particle was observed due to the rapid solute diffusion in liquid steel. During solidification, titanium nitride precipitates on a primary inclusion particle including Ca-modified Al-Mg oxides which precipitates at temperatures lower than $1600^{\circ} \mathrm{C}$. In view of these facts, is more plausible that $\mathrm{CaO} \cdot \mathrm{MgO} \cdot \mathrm{Al}_{2} \mathrm{O}_{3}$ nucleated on TiN inclusions precipitated in the melt at high temperatures and later, after matrix solidification, the further growth of TiN partially or completely embedded the $\mathrm{CaO} \cdot \mathrm{MgO} \cdot \mathrm{Al}_{2} \mathrm{O}_{3}$ particles. The TiN continues to grow during solidification and covers the particles of Ca-modified Al-Mg oxides which precipitated during solidification at temperatures below $1600^{\circ} \mathrm{C}$.

According literature ${ }^{27,30}$, the $\mathrm{MgO}$ and $\mathrm{Al}_{2} \mathrm{O}_{3}$ refractory material are picked up during melting of the 690 alloy and can act as seeds for the formation of TiN inclusions during the solidification process. Hur et al. ${ }^{30}$ have shown that microvoids in Ti precipitates can act as stress concentrator, having a deleterious effect on the chemical and mechanical properties of $\mathrm{Ni}-\mathrm{Cr}-\mathrm{Fe}$ alloys.

Lian et al. ${ }^{31}$ studied the effect of titanium content on the microstructure and mechanical properties of SMSS. They reported ${ }^{31}$ that the Ti addition to SMSS promotes a microstructural refinement, with a decrease of the prior austenite grain size and lath martensite width.

According Lian et al. ${ }^{31}$, Ti possesses a higher carbon and nitrogen affinity than $\mathrm{Cr}$, therefore, for a given titanium content, all of the carbon and nitrogen content can precipitate as titanium carbonitrides to prevent chromium carbide precipitation. The authors ${ }^{31}$ also described that the micro addition of $0.2 \mathrm{Ti}$ (wt.\%) suppressed the formation of $\mathrm{Cr}$-rich carbides by forming stable TiN which retards the formation of the reversed austenite and enhances strength without severe decrease in toughness. The SMSS has 0.17 wt. $\%$ of Ti and the formation of TiN occurred as reported in literature ${ }^{31}$. AlN was not find in the steel microstructure mainly because the content of titanium in steel is $0.17 \mathrm{wt} . \%$ and the concentration of aluminum is only $0.015 \mathrm{wt} . \%$. Besides that, the melting point of $\mathrm{TiN}$ is $2930^{\circ} \mathrm{C}$, higher than the melting point of AlN which is $2200^{\circ} \mathrm{C}$, indicating a higher stability of TiN than AIN.

Literature ${ }^{31}$ also reported that the micro addition of $0.5 \mathrm{Ti}$ (wt.\%) leads to the nano-intermetallic precipitation of $\mathrm{Ni}_{3} \mathrm{Ti}$ instead of titanium carbonitrides in SMSS after tempering at $600^{\circ} \mathrm{C}$ for $4 \mathrm{~h}$. According Carrouge ${ }^{32}$, the excessive Ti additions lead to the precipitation of intermetallic compounds such as TiNi instead of TiCN. Rodrigues et al. ${ }^{6}$ evaluated the effect of addition of $0.13 \mathrm{Ti}$ (wt.\%) in a $12.5 \mathrm{Cr}-5.4 \mathrm{Ni}-$ $2.09 \mathrm{Mo}$ (wt.\%) SMSS. According Carrouge ${ }^{32}$ the addition of $0.13 \mathrm{Ti}$ (wt.\%) after a selected heat treatment produced a very fine refined microstructure composed of martensite matrix with nanometer size particles of titanium carbonitride ( $\mathrm{TiCN}-70 \mathrm{~nm}$ ), which was responsible for the improved mechanical property. The as-quenched steel showed a microhardness of $275.43 \pm 2.36 \mathrm{HV}$ and the tempered steel showed a microhardness of $260.77 \pm 9.43 \mathrm{HV}^{32}$.

Figure 4 shows the X-ray diffraction patterns of the SMSS as quenched and after tempering. The Miller indices corresponding to martensite and retained austenite are indicated in Figure 4. Low intensity austenite peaks and high intensity martensite peaks were observed for all conditions, as 
(b)

(a)

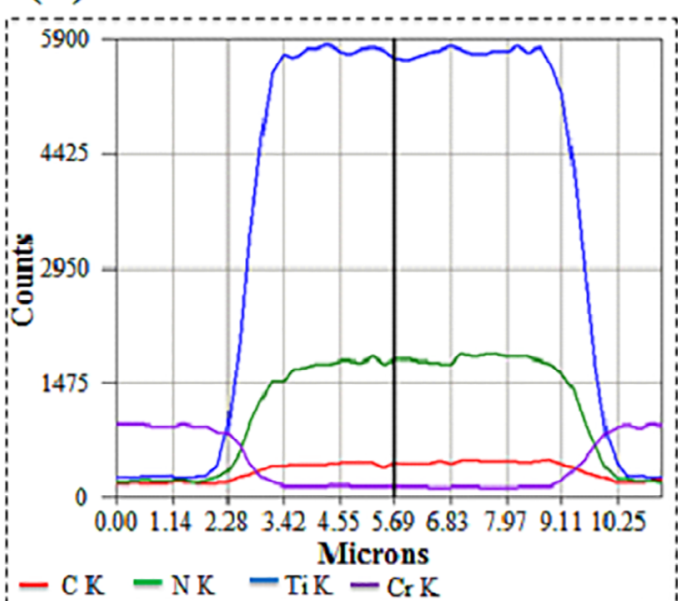

(d)

(c)

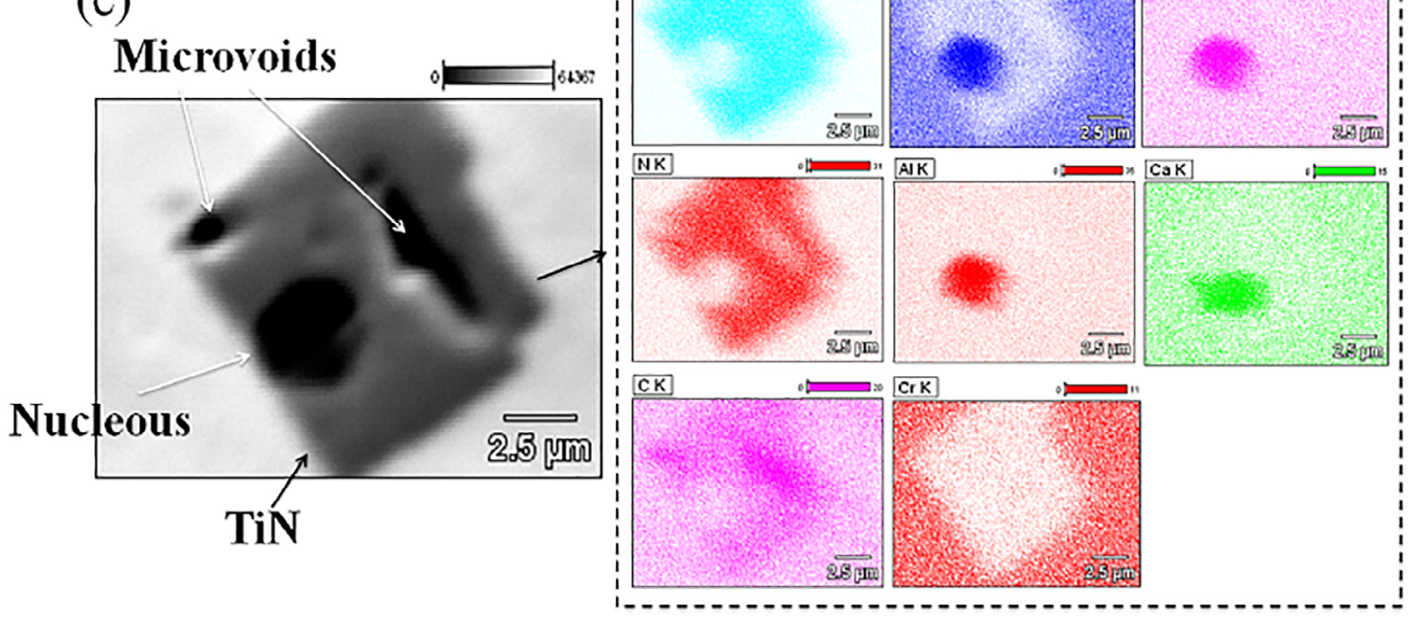

(f)

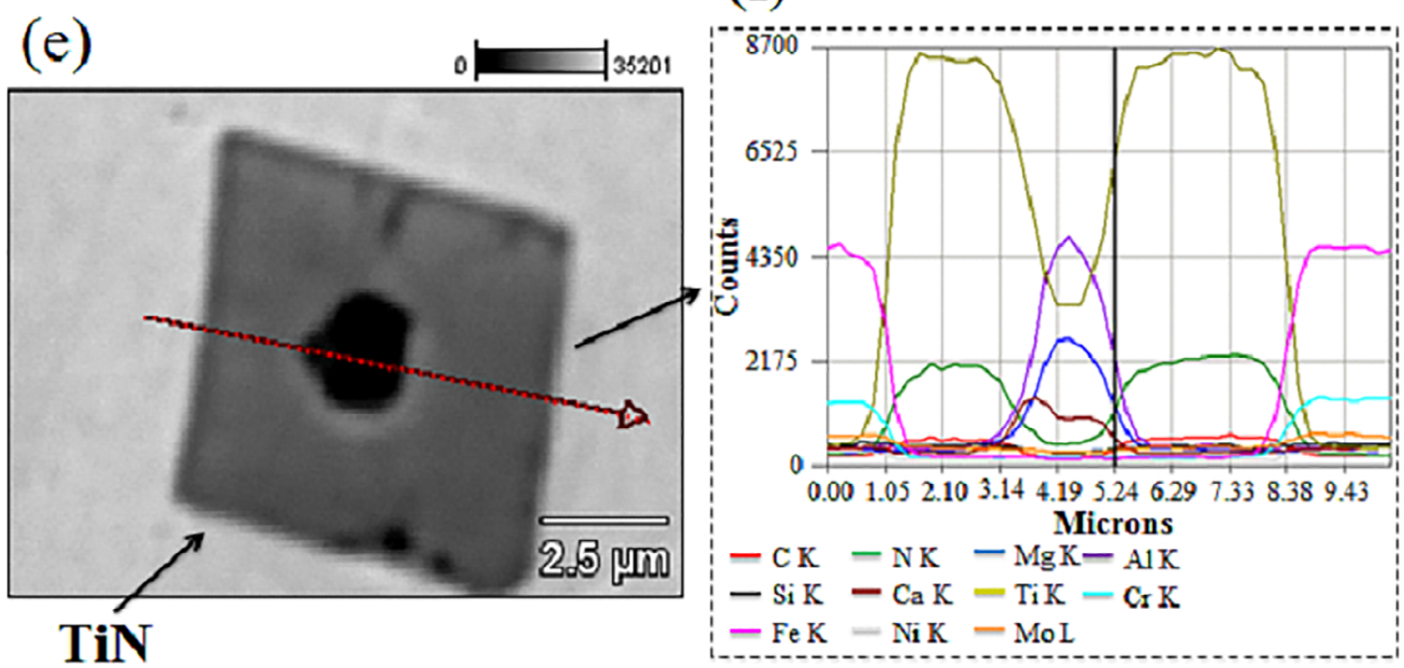

Figure 2. (a, c, e) SEM micrographs of three different inclusions on the SMSS surface with a darker contrast in the back scattering detector of SEM, which could be identified as TiN by EDS analysis $(b, d, f)$. 


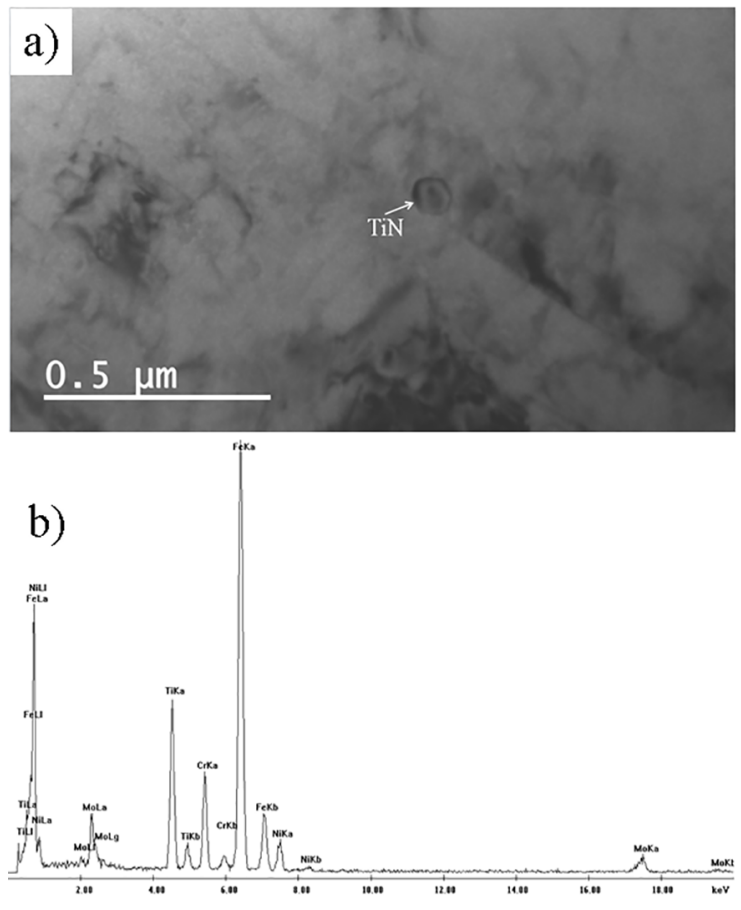

Figure 3. (a) Transmission electron micrograph of TiN on the SMSS surface and (b) EDS spectrum of TiN precipitate indicated in (a).
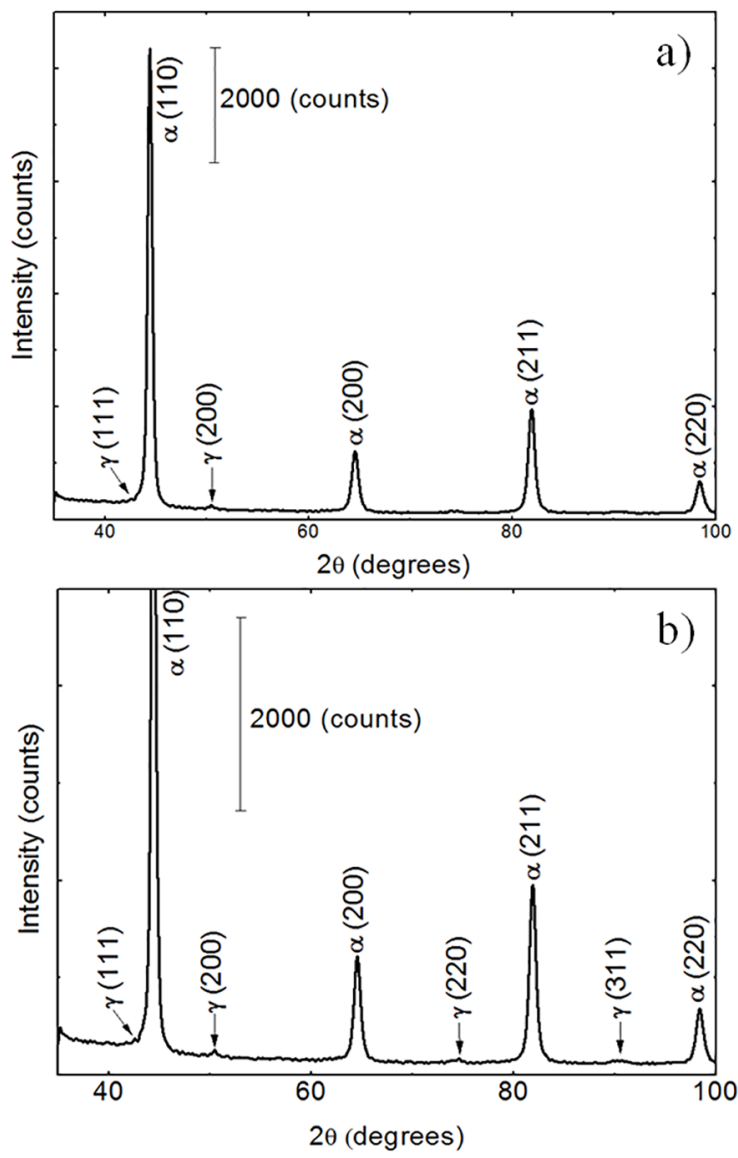

Figure 4. (a) X-Ray diffraction of the supermartensitic steel tempering at a temperature range of $600-640^{\circ} \mathrm{C}$ and (b) Magnification of diffractogram to show low intensity peaks. shown in Fig. 4. The (111), (200), (220), and (311) austenite diffraction peaks had low intensity when compared to the martensite peaks for all conditions. The amount of retained austenite was too low for a quantitative determination of its the volume fraction by the Rietveld method.

According to Solomon and Levinson ${ }^{21}$, a Mössbauer spectrum results from the resonant absorption of 14.4 $\mathrm{keV} \gamma$-rays by the ${ }^{57} \mathrm{Fe}$ iron nuclei. When these nuclei are in a ferromagnetic arrangement, as in the case of the $\alpha \mathrm{Fe}$ below the Curie point, a six-line absorption pattern is observed. However, if the ${ }^{57} \mathrm{Fe}$ nucleus in the $\alpha \mathrm{Fe}$ is in a paramagnetic state, then a single paramagnetic resonant line will be observed. For any sample, if a paramagnetic ${ }^{57} \mathrm{Fe}$ occurs in the sample along with the magnetically ordered $\alpha \mathrm{Fe}$ phase, the corresponding spectrum will be the superposition of six-peak ferromagnetic spectrum with the single-line paramagnetic spectrum.

The Mössbauer spectroscopy results for the tempered sample are shown in Table 2 and Figure 5. The Mössbauer spectra showed the existence of at least two chemical environments which are associated with iron site with different neighborhoods. The chemical environment where the ${ }^{57} \mathrm{Fe}$ atoms are surrounded mostly by other ${ }^{57} \mathrm{Fe}$ atoms have higher hyperfine fields, characterized in Figure 5 by the set of sextet (gray lines), with hyperfine parameters typical of the alpha phase $(\alpha)$ magnetic (martensitic) with $99.1 \%$ of the spectral areas. And another chemical environment was identified in Figure 5, characterized by a singlet (red line), with a range of parameters typical of the hyperfine phase ( $\gamma$, austenitic) non-magnetic, with less than $1 \%$ of the spectral area.

The Mössbauer spectroscopy results for the tempered sample showed that austenite dispersed in the martensite has a content lower than 1at.\%.

The microstructure of the SMSS, tempered for $30 \mathrm{~min}$ at a temperature range of $600-640^{\circ} \mathrm{C}$, was also evaluated by the EBSD technique. Figure 6 shows the misotexture of tempered sample. After different heat-treatments, grains showed a similar plate-like shape. According to Bilmes et al. ${ }^{33}$, retained austenite has a plate shape when found within the martensite matrix and at prior austenite grain boundaries after tempering. The black line indicates the grain boundaries with misorientation above $15^{\circ}$. The prior austenite grain boundaries were found with misorientation above $15^{\circ}$.

Figure 7 shows the phase map, where martensite grains are in red, austenite in blue, and high angle grain boundaries are marked by black lines. As expected, the martensite covered almost the entire examined surface, which means that there is no extend austenite in this microstructure. Retained austenite, which was identified by arrows, has a globular morphology and can be mainly found at high angle boundaries in the martensitic matrix (Figure 7).

The grain size data collected from EBSD data for tempered samples were given by the histogram shown in Figure 8 . The sample showed a marked asymmetrically behavior. The descriptive data were shown in Table 3 . 
Table 2. Mössbauer Spectroscopy results for tempered sample.

\begin{tabular}{|c|c|c|c|c|}
\hline \multirow{2}{*}{ Sample } & \multirow{2}{*}{ Phase Identification } & \multicolumn{2}{|c|}{ Isomeric shift } & \multirow{2}{*}{ Phase $( \pm 0.5) \%$} \\
\hline & & d $( \pm 0,05) \mathrm{mm} / \mathrm{s}$ & $\mathrm{H}_{\mathrm{HF}}( \pm \mathbf{0 , 5})$ Tesla & \\
\hline Tempered & $\alpha$ & -0.01 & $<27.1>$ & 99.1 \\
\hline SMSS & $\gamma$ & -0.09 & - & 0.9 \\
\hline
\end{tabular}

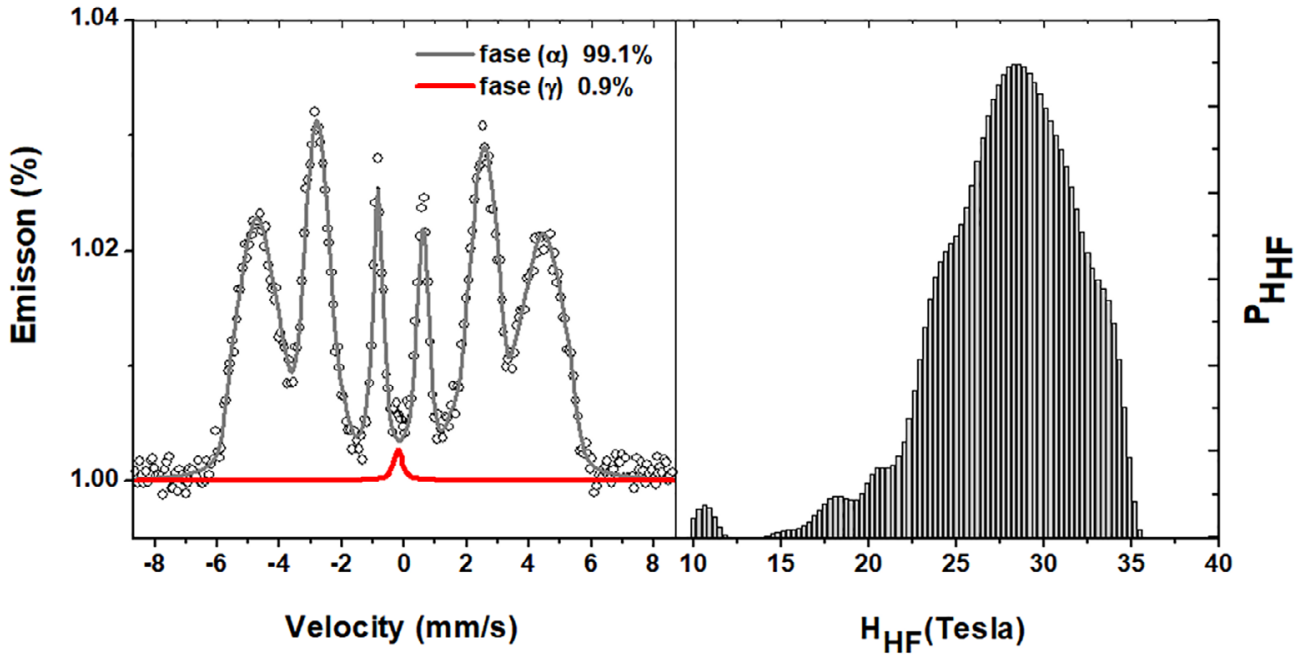

Figure 5. Mössbauer spectroscopy results of tempered SMSS.
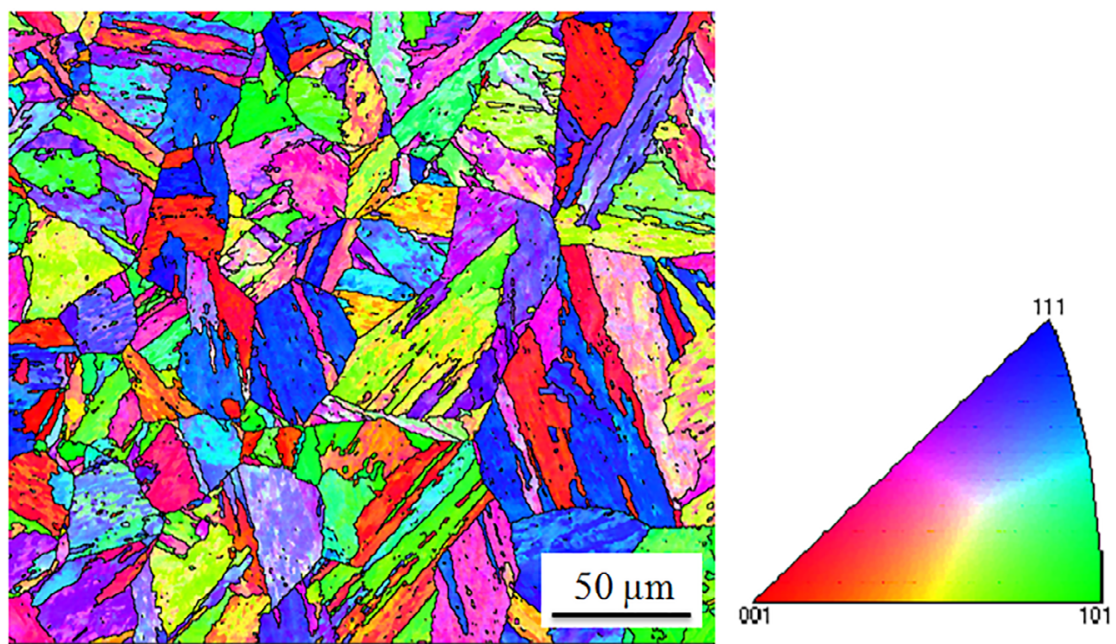

Figure 6. Orientation image maps for the supermartensitic steel samples after tempering for $30 \mathrm{~min}$ at a temperature range of $600-640^{\circ} \mathrm{C}$.

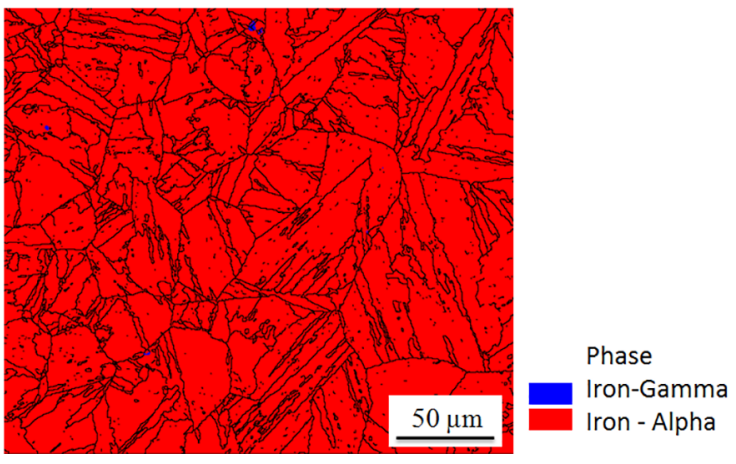

Figure 7. EBSD phase map for the supermartensitic steel samples after tempering for $30 \mathrm{~min}$ at a temperature range of $600-640^{\circ} \mathrm{C}$.

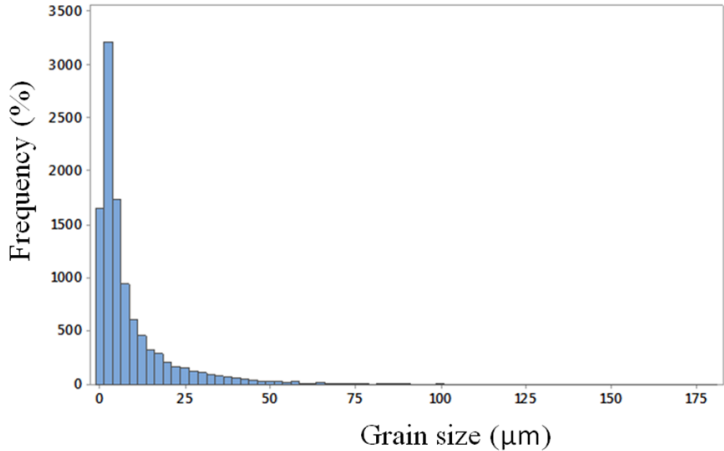

Figure 8. Grain size distribution $(\mu \mathrm{m})$ of the tempered SMSS sample. 
Table 3. Descriptive statistics of grain size data collected from EBSD data for tempered SMSS sample.

\begin{tabular}{lcccc}
\hline Grain size $(\boldsymbol{\mu m})$ & Mean & Median & Minimun & Maximum \\
\hline Tempered SMSS & $9.174 \pm 13.154$ & 4.231 & 0.846 & 179.440 \\
\hline
\end{tabular}

\subsection{Corrosion resistance evaluation}

Figure 9 shows typical cyclic polarization curves of SMSS samples in $0.1 \mathrm{~mol} / \mathrm{L} \mathrm{NaCl}$ solution. The pitting potential was $93.31 \pm 3.86 \mathrm{mV}(\mathrm{Ag} / \mathrm{AgCl})$. A repassivation was not observed during the reverse scan after stable pits have formed above the breakdown potential and the localized corrosion has spread to $1.7 \mathrm{~mA} / \mathrm{cm}^{2}$. Anodic dissolution and oxide formation occurred prior to pitting process and can also be observed in Figue 9.

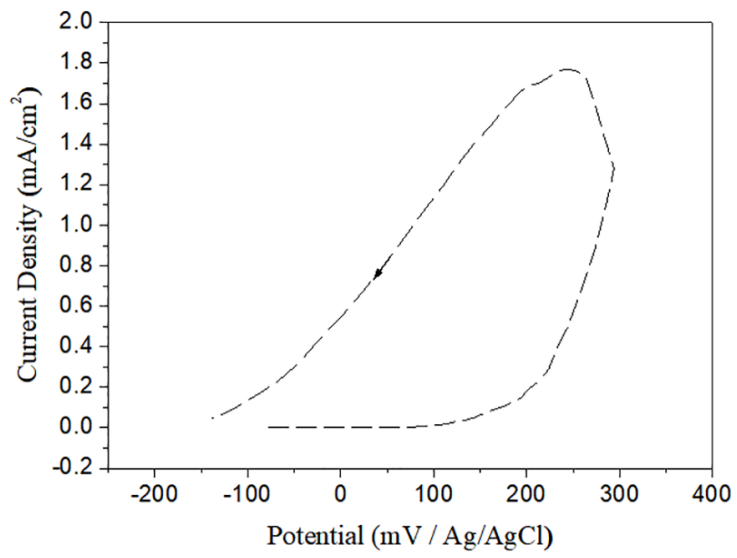

Figure 9. Cyclic polarization curves of tempered SMSS sample in $0.1 \mathrm{~mol} / \mathrm{L} \mathrm{NaCl}$ aqueous solution at $1 \mathrm{mV} / \mathrm{s}$.

Representative curves of the OCP evolution with the immersion time for the tempered SMSS sample are presented in Figure 10. Transient currents may be observed for the tempered sample and are indicated by arrows in Figure 10. These transient currents are indicative of a pitting process with metastable pits forming and repassivating at a potential below of breakdown potential.

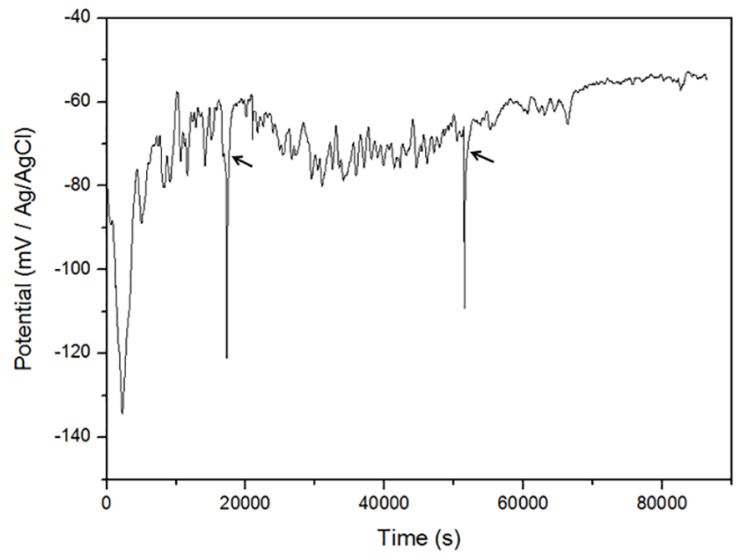

Figure 10. OCP of tempered SMSS sample acquired during $86400 \mathrm{~s}$ in $0.1 \mathrm{~mol} / \mathrm{L} \mathrm{NaCl}$ aqueous solution.
The SVET maps obtained for the tempered SMSS sample after $3600 \mathrm{~s}$ and after $86400 \mathrm{~s}$ of immersion in a $0.1 \mathrm{M} \mathrm{NaCl}$ solution, as well as the optical image of the respective surface after the immersion are shown in Figure 11.
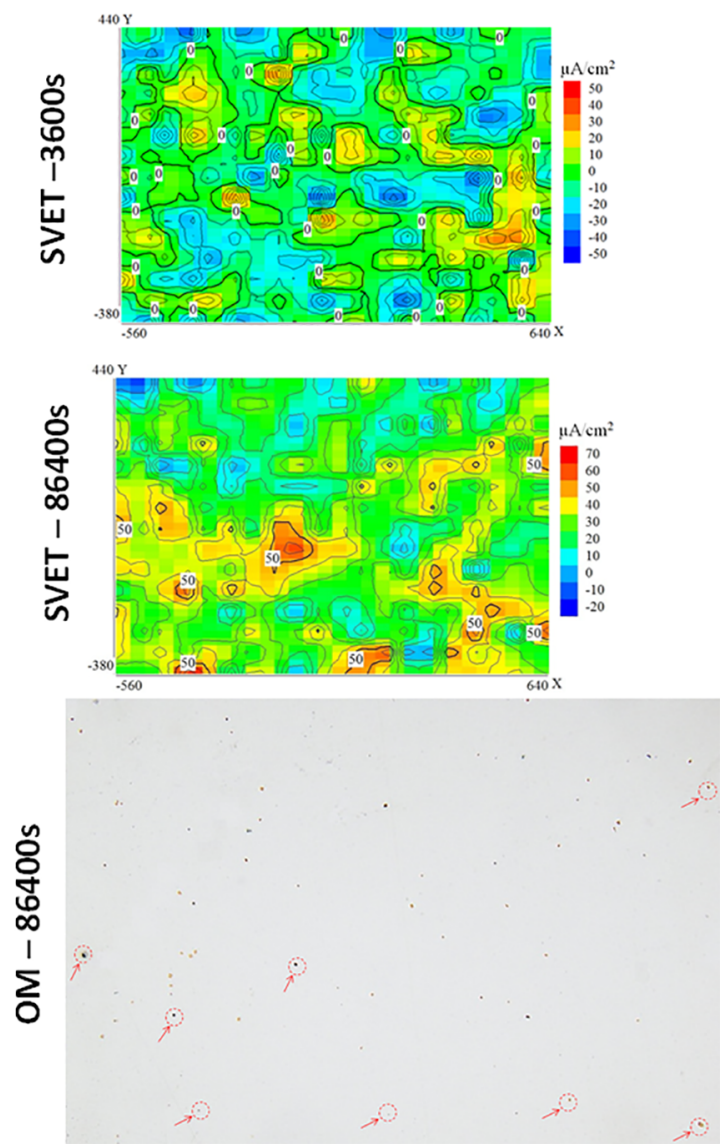

Figure 11. SVET images and optical micrographs (OM) of tempered SMSS surface immersed in $0.1 \mathrm{~mol} / \mathrm{L} \mathrm{NaCl}$. Pit locations are indicated by red circles and arrows in micrograph.

The tempered SMSS sample showed no activity after immersion in a $0.1 \mathrm{M} \mathrm{NaCl}$ solution, after $3600 \mathrm{~s}$. However, after the 86400 s of immersion in a saline solution, a pit has developed. The optical image of tempered sample showed that the anodic sites on the steel surface have developed around the TiN particles (Figures 12 and 13).

The SEM micrograph and EDS concentration maps of the tempered sample after SVET measurement are shown in Figure 13, where a localized corrosion around the TiN particles may be observed, as those recorded in the SVET experiments. The EDS concentration maps showed that these precipitates are enriched in Ti compared to the steel matrix.

The TiN inclusions, as nonmetallic particles, hardly dissolve in high-temperature water due to their excellent 


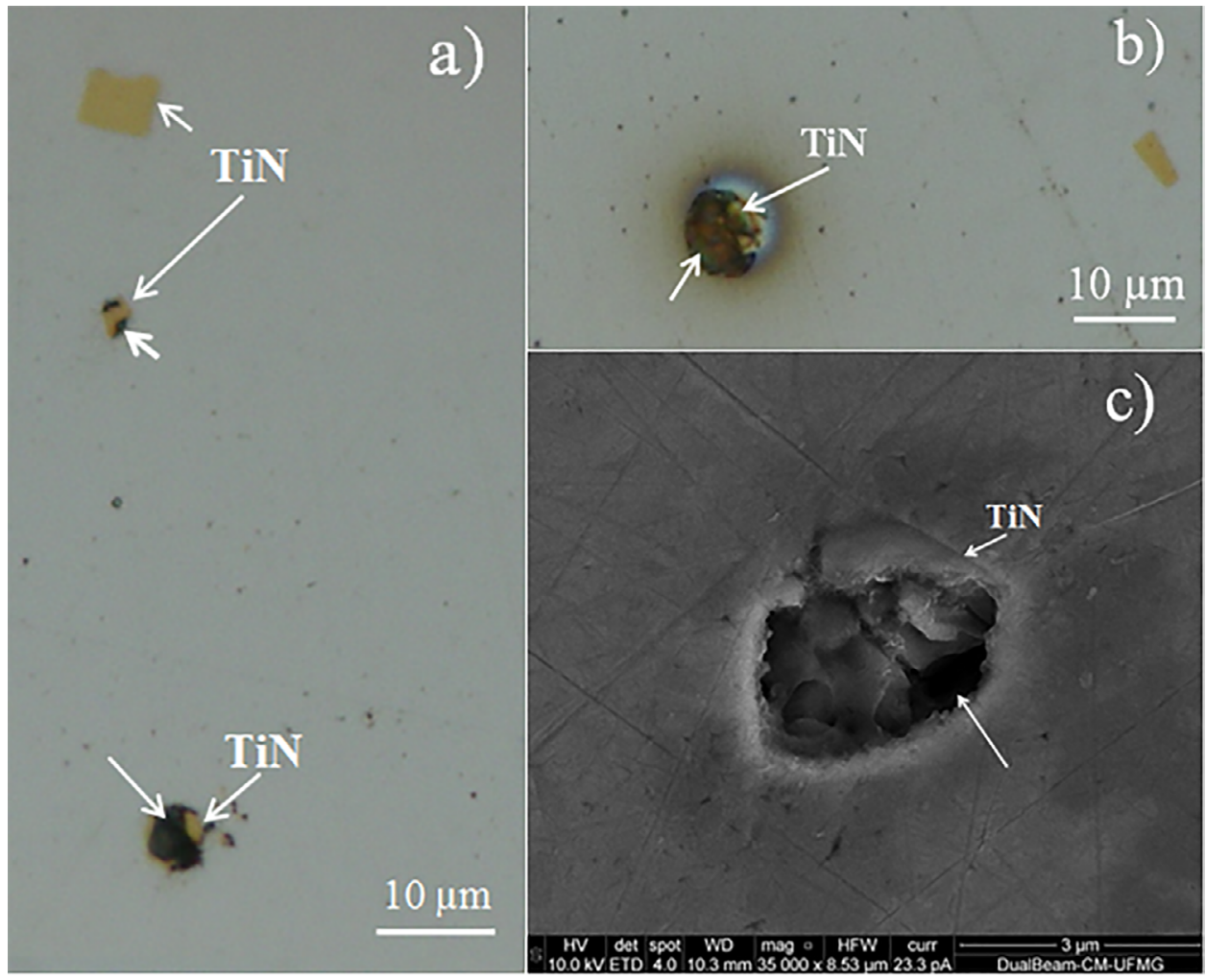

Figure 12. (a, b) Optical micrographs and (c) SEM images of tempered sample surface immersed in $0.1 \mathrm{~mol} / \mathrm{L} \mathrm{NaCl} \mathrm{during} 86400 \mathrm{~s}$. Pit locations are indicated by white arrows in micrographs.

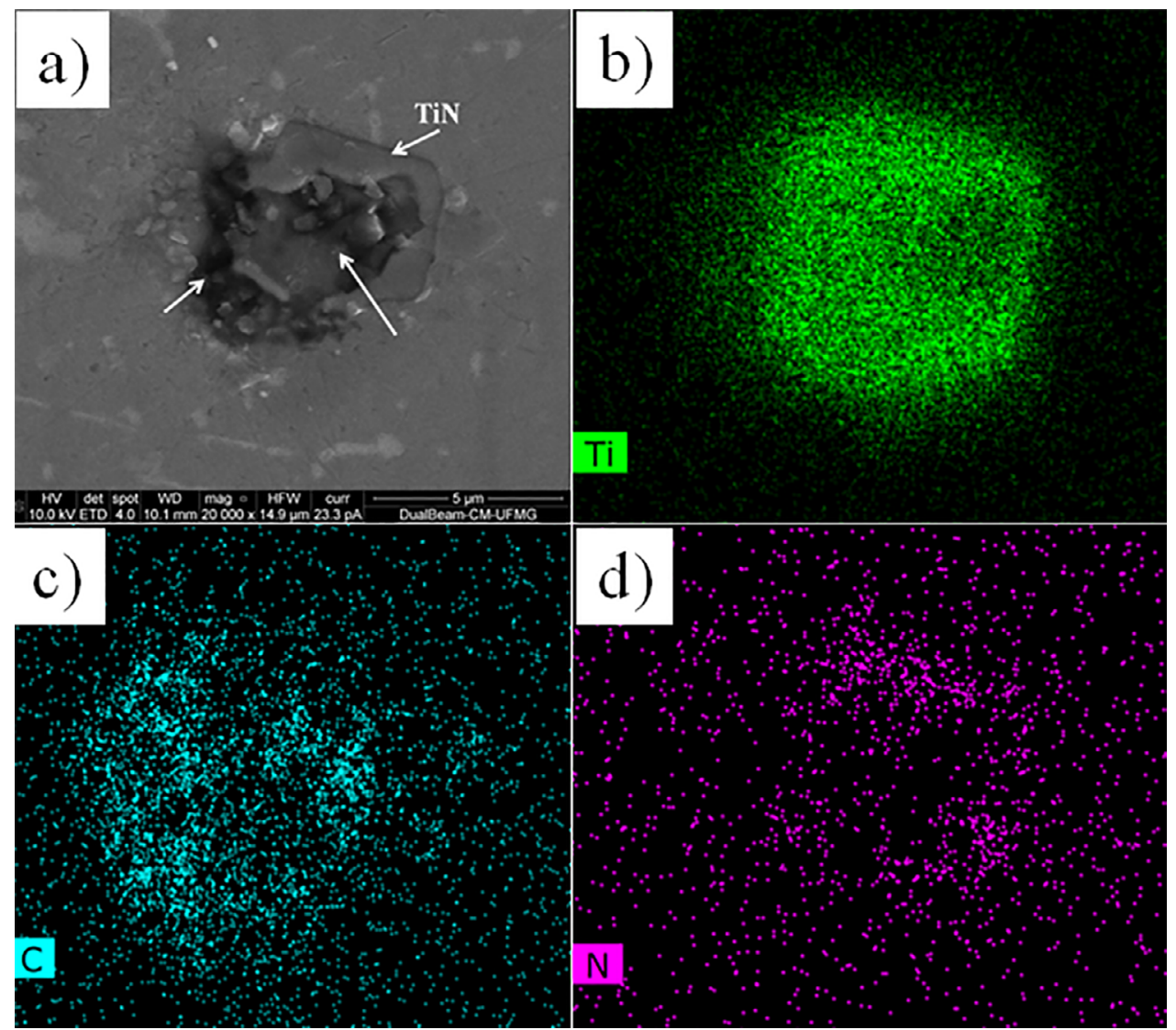

Figure 13. (a) SEM micrograph and (b, c, d) EDS concentration maps of the tempered sample after SVET measurement during 86400 s. 
electrochemical stability and usually behave as cathodes under corrosive environments ${ }^{34,35}$. In contrast, $\mathrm{Al}_{2} \mathrm{O}_{3}$ and/or $\mathrm{MgO}$ are not thermodynamically stable because their free potentials are lower than that of the matrix ${ }^{36}$. Literature reported that large, faceted titanium nitride inclusions, which have a hexagonal crystal structure, can act as passive film breakdown sites in the alloy 690 , and they can also provide preferential sites for pit initiation in an acidic chloride environment ${ }^{27}$.

Hur et al. ${ }^{30}$ showed that the microvoids between the fragments of broken Ti-carbonitrides accelerated pitting corrosion around the inclusion. Even the exposed TiN stringer without microvoids still acts as a cathode to benefit the localized corrosion at the steel region near the precipitate.

According to Dutta et al ${ }^{26}$, faceted titanium nitride particles in Alloy 800 may provide preferred sites for pit initiation in chloride environments. The presence of large, faceted titanium nitride particles in Alloy 800 has been found to be more detrimental than the small, spherical-shaped titanium carbide particles as far as the surface-related localized corrosion resistance of the alloy in chloride environments.

Theories for passive film breakdown and pit initiation have been summarized in three main mechanisms that focus on passive film penetration, film breaking, or adsorption ${ }^{37,38}$. These three mechanisms of pit initiation are not necessarily mutually exclusive. In this study, a combination of these mechanisms is possible. According to Marcus et al. ${ }^{39}$, the presence of microstructural defects on the samples such as grain boundaries or interfaces between the matrix and inclusions or second phase particles can promote local breakdown of the passive film. In this work, the breakdown of the passive film was found to be associated with the TiN.

According to $\operatorname{Tan}^{40}$, the electrode inhomogeneity such as titanium nitride particles, grain boundaries appears to determine the pitting nucleation stage while the electrochemical heterogeneity, that is believed to initiate from pre-existing active anodic sites such as around the TiN particles, appears to control the propagation stage. Frankel et al. ${ }^{38}$ discussed the critical step in localized corrosion. Some researchers consider the protectiveness of passive film and its initial breakdown, whereas others consider that the pit growth kinetics and the stabilization of pit growth are main factors to control localized corrosion. Frankel et al. ${ }^{38}$ reported that both situations can occur depending on the aggressiveness of the environment. In the present work, the protection efficiency of passive film is not high, the passive film breakdown and production of metastable pit are fast. The critical step of the localized corrosion process can be the pit growth, based on Ref. 38 .

It has been proposed by some author ${ }^{39,41-43}$ that adsorption of aggressive anions $\left(\mathrm{Cl}^{-}\right)$reduces the surface tension of the passive film leading to cracks, allowing anions to reach the metal surface. Marcus et al. ${ }^{39}$ have shown evidence for both chloride adsorption and penetration for the pitting corrosion in chloride solutions. If $\mathrm{Cl}^{-}$ions are present in the electrolyte, they will compete with $\mathrm{OH}^{-}$for adsorption on the oxide surface ${ }^{40,43,44} . \mathrm{Cl}^{-}$can penetrate through intergranular boundaries and migrate to the metal/oxide interface, resulting in the formation of $\mathrm{Cl}^{-}$containing particles that will cause stress-induced fracture of the passive film due to the growth of these particles ${ }^{39}$.

\section{Conclusions}

Microstructural and electrochemical analyses of SMSS submitted to austenitizing at $1000^{\circ} \mathrm{C}$, water quenching, tempering at a temperature range of $600-640^{\circ} \mathrm{C}$ and air cooling were performed. The steel characterization techniques used were Mössbauer, SEM and OM, TEM, EDS, XRD, EBSD, SVET and cyclic polarization.

Coarse cuboidal TiN particles were identified on the steel surface of the sample. The TiN inclusions showed microvoids and a nucleus containing magnesium, aluminum and calcium oxides.

Mössbauer spectroscopy identified $0.9 \%$ of retained austenite in SMSS sample tempered at a temperature range of $600-640^{\circ} \mathrm{C}$.

The sample tempered at a temperature range of $600-640^{\circ} \mathrm{C}$ showed a maximum grain size of $179.44 \mu \mathrm{m}$ evaluated by using EBSD technique.

The SMSS sample showed no electrochemical activity after 3600 s of immersion in a saline solution by using a SVET technique, but after 86400 s, a pit was detected. SVET analysis showed the association of a localized corrosion sites with the TiN inclusion on the steel surface.

\section{Acknowledgments}

Authors would like to thank governmental agencies: Conselho Nacional de Desenvolvimento Científico e Tecnológico (CNPq), Coordenação de Aperfeiçoamento de Pessoal de Nível Superior (CAPES), Fundação de Amparo à Pesquisa do Estado de Minas Gerais (FAPEMIG), Centro de Microscopia da UFMG, Laboratório Nacional de Nanotecnologia (LNNano/CNPEM), and Centro de Desenvolvimento da Tecnologia Nuclear (CDTN).

\section{References}

1. Ye D, Li J, Jiang W, Su J, Zhao K. Effect of Cu addition on microstructure and mechanical properties of $15 \% \mathrm{Cr}$ supermartensitic stainless steel. Materials and Design. 2012;41:16-22.

2. Zou DN, Han Y, Zhang W, Fang XD. Influence of tempering process on mechanical properties of $00 \mathrm{Cr} 13 \mathrm{Ni} 4 \mathrm{Mo}$ supermartensitic stainless steel. Journal of Iron and Steel Research International. 2010;17(8):50-54.

3. Rovere CAD, Ribeiro CR, Silva R, Baroni LFS, Alcântara NG, Kuri SE. Microstructural and mechanical characterization of radial friction welded supermartensitic stainless steel joints. Materials Science and Engineering: A. 2013;586:86-92. 
4. Ma XP, Wang LJ, Liu CM, Subramanian SV. Role of Nb in low interstitial $13 \mathrm{Cr}$ super martensitic stainless steel. Materials Science and Engineering: A. 2011;528(22-23):6812-6818.

5. Ma XP, Wang LJ, Liu CM, Subramanian SV. Microstructure and properties of $13 \mathrm{Cr} 5 \mathrm{Ni} 1 \mathrm{Mo} 0.025 \mathrm{Nb} 0.09 \mathrm{~V} 0.06 \mathrm{~N}$ supermartensitic stainless steel. Materials Science and Engineering: A. 2012;539:271-279.

6. Rodrigues CAD, Lorenzo PLD, Sokolowski A, Barbosa CA, Rollo JMDA. Titanium and molybdenum content in supermartensitic stainless steel. Materials Science and Engineering: A . 2007;460461:149-152.

7. Ilevbare GO, Burstein GT. The role of alloyed molybdenum in the inhibition of pitting corrosion in stainless steels. Corrosion Science. 2001;43(3):485-513.

8. Bastidas JM, Torres CL, Cano E, Polo JL. Influence of molybdenum on passivation of polarised stainless steels in a chloride environment. Corrosion Science. 2002;44(3):625-633.

9. Calliari I, Zanesco M, Dabala M, Brunelli K, Ramous E. Investigation of microstructure and properties of a Ni-Mo martensitic stainless steel. Materials and Design. 2008;29:246-250.

10. Mesquita TJ, Chauveau E, Mantel M, Bouvier N, Koschel D. Corrosion and metallurgical investigation of two supermartensitic stainless steels for oil and gas environments. Corrosion Science. 2014;81:152-161.

11. Pereda MD, Gervasi CA, Llorente CL, Bilmes PD. Microelectrochemical corrosion study of super martensitic welds in chloride-containing media. Corrosion Science. 2011;53(12):3934-3941.

12. Zou DN, Liu XH, Han Y, Zhang W, Li J, Wu K. Influence of heat treatment temperature on microstructure and property of 00Crl3Ni5Mo2 supermartensitic stainless steel. Journal of Iron and Steel Research International. 2014;21(3):364-368.

13. Moreto JA, Marino CEB, Bose Filho WW, Rocha LA, Fernandes JCS. SVET, SKP and EIS study of the corrosion behaviour of high strength $\mathrm{Al}$ and $\mathrm{Al}-\mathrm{Li}$ alloys used in aircraft fabrication. Corrosion Science. 2014;84:30-41.

14. Santos AP, Manhabosco SM, Rodrigues JS, Dick LFP. Comparative study of the corrosion behavior of galvanized, galvannealed and Zn55Al coated interstitial free steels. Surface and Coatings Technology. 2015;279:150-160.

15. Manhabosco SM, Santos AP, Marcolin ML, Pieretti EF, Neves MDM, Dick LFP. Localized corrosion of laser marked M340 martensitic stainless steel for biomedical applications studied by the scanning vibrating electrode technique under polarization. Electrochimica Acta. 2016;200:189-196.

16. Pieretti EF, Manhabosco SM, Dick LFP, Hinder S, Costa I. Localized corrosion evaluation of the ASTM F139 stainless steel marked by laser using scanning vibrating electrode technique, X-ray photoelectron spectroscopy and Mott-Schottky techniques. Electrochimica Acta. 2014;124:150-155.

17. Manhabosco SM, Batista RJC, Silva SN, Dick LFP. Determination of current maps by svet of hot-dip galvanized steel under simultaneous straining. Electrochimica Acta. 2015;168:89-96.

18. Bertoncello JCB, Manhabosco SM, Dick LFP. Corrosion study of the friction stir lap joint of AA7050-T76511 on AA2024-T3 using the scanning vibrating electrode technique. Corrosion Science. 2015;94:359-367.
19. Brand RA. Improving the validity of hyperfine field distributions from magnetic alloys: Part I: Unpolarized source. Nuclear Instruments and Methods in Physics Research: B. 1987;28(3):398-416.

20. Lemoine C, Fnidiki A, Danoix F, Hédin M, Teillet J. Mössbauer and atom probe studies on the ferrite decomposition in duplex stainless steels caused by the quenching rate. Journal of Physics: Condensed Matter. 1999;11:1105.

21. Solomon HD, Levinson LM. Mössbauer effect study of $475^{\circ} \mathrm{C}$ embrittlement of duplex and ferritic stainless steel. Acta Metallurgica. 1978;26(3):429-42.

22. Vignal V, Ba D, Zhang H, Herbst F, Le Manchet S. Influence of the grain orientation spread on the pitting corrosion resistance of duplex stainless steels using electron backscatter diffraction and critical pitting temperature test at the microscale. Corrosion Science. 2013;68:275-278.

23. Yang L, Webler BA, Cheng GG. Precipitation behavior of titanium nitride on a primary inclusion particle during solidification of bearing steel. Journal of Iron and Steel Research International. 2017;24:685-690.

24. Michelic SK, Loder D, Reip T, Barani AA, Bernhard C. Characterization of $\mathrm{TiN}, \mathrm{TiC}$ and $\mathrm{Ti}(\mathrm{C}, \mathrm{N})$ in titanium-alloyed ferritic chromium steels focusing on the significance of different particle morphologies. Materials Characterization. 2015;100:61-67.

25. Shi C, Cheng GG, Li ZJ, Zhao P. Solidification structure refining of 430 Ferrite stainless steel with TiN nucleation. Journal of Iron and Steel Research International. 2008;15(3):57-60.

26. Dutta RS, Purandare R, Lobo A, Kulkarni SK, Dey GK. Microstructural aspects of the corrosion of Alloy 800. Corrosion Science. 2004;46:2937-2953.

27. Meng F, Wang J, Han EH, Ke W. The role of TiN inclusions in stress corrosion crack initiation for Alloy 690TT in hightemperature and high-pressure water. Corrosion Science. 2010;52(3):927-932.

28. Shi CB, Yu WT, Wang H, Li J, Jiang M. Simultaneous modification of alumina and $\mathrm{MgO} . \mathrm{Al}_{2} \mathrm{O}_{3}$ inclusions by calcium treatment during electroslag remelting of stainless tool steel. Metallurgical and Materials Transactions: B. 2017;48(1):146-161.

29. Salomão R, Ferreira VL, Oliveira IR. Evolução da microestrutura do hexaluminato de cálcio formado "in situ" para obtenção de cerâmicas refratárias porosas. In: $60^{\circ}$ Congresso Brasileiro de Cerâmica; 2016 mai 15-18; Águas de Lindóia, São Paulo, Brasil. Águas de Lindóia (SP): Associação Brasileira de Cerâmica; 2016.

30. Hur DH, Han JH, Lee UC, Park YS. Microchemistry of Ticarbonitrides and their role in the early stage of pit initiation of alloy 600. Corrosion. 2006;62(7):591-597.

31. Lian Y, Huang J, Zhang J, Zhang C, Gao W, Zhao C. Effect of 0.2 and $0.5 \% \mathrm{Ti}$ on the microstructure and mechanical properties of $13 \mathrm{Cr}$ supermartensitic stainless steel. Journal of Materials Engineering and Performance. $2015 ; 24: 4253-4259$.

32. Carrouge D. Transformations in supermartensitic stainless steels [thesis]. Cambridge, UK: University of Cambridge; 2002. 
33. Bilmes PD, Solari M, Llorente CL. Characteristics and effects of austenite resulting from tempering of $13 \mathrm{CrNiMo}$ martensitic steel weld metals. Materials Characterization. 2001;46(4):285-296.

34. Briant CL, Ritter AM. The effects of deformation induced martensite on the sensitization of austenitic stainless steels. Metallurgical and Materials Transactions: A. 1980;11:2009-2017.

35. Briant CL, Ritter AM. The effect of gold work on the sensitization of 304 stainless steel. Scripta Metallurgica. 1979;13(3):177-181.

36. Jha AK, Sivakumar D, Sreekumar K, Mittal MC. Role of transformed martensite in the cracking of stainless steel plumbing lines. Engineering Failure Analysis. 2008;15(8):1042-51.

37. Frankel GS. Pitting corrosion of metals. Journal of The Electrochemical Society. 1998;145:2186.

38. Frankel GS, Li T, Scully JR. Localized corrosion: passive film breakdown vs pit growth stability. Journal of The Electrochemical Society. 2017;164(4):C180-C181.
39. Marcus P, Maurice V, Strehblow HH. Localized corrosion (pitting): a model of passivity breakdown including the role of the oxide layer nanostructure. Corrosion Science. 2008;50:2698-2704.

40. Tan Y. Understanding the effects of electrode inhomogeneity and electrochemical heterogeneity on pitting corrosion initiation on bare electrode surfaces. Corrosion Science. 2011;53(5):1845-1864.

41. Baker MA, Castle JE. The initiation of pitting corrosion of stainless steels at oxide inclusions. Corrosion Science. 1992;33(8):1295-1312.

42. Hoar TP. The production and breakdown of the passivity of metals. Corrosion Science. 1967;7(6):341-355.

43. Sato N. An overview on the passivity of metals. Corrosion Science. 1990;31:1-19.

44. Soltis J. Passivity breakdown, pit initiation and propagation of pits in metallic materials - review. Corrosion Science. 2015;90:5-22. 